\title{
A surveillance study of antibiotic use in Pondicherry- 2012
}

\author{
Revathysaravanan*, G.L. Arun Muthukumar
}

${ }^{a}$ Department of Pharmacology, Sri Venkateshwaraa Medical College Hospital \& Research Centre, Ariyur, Pondicherry605102, India

Received: 13 October 2012

Revised: 2 November 2012

Accepted: 4 November 2012

*Correspondence to:

Dr. Revathysaravanan,

Email: dr_rsmail@yahoo.co.in

\begin{abstract}
Background: An alarming increase in antibiotic use and antimicrobial resistance especially in India is reported by WHO based on the reports from 5 pilot projects. As WHO and GARP India Working Group State have stressed the importance of repeated co-ordinate surveillance to monitor, this study is undertaken in Pondicherry with the objectives of identifying Commonly used antibiotics, the most exposed age group in Pondicherry and the determining factors for inappropriate use of antibiotics among professionals and community.
\end{abstract}

Methods: A surveillance study was done by using convenient sampling technique on 50 physicians and 100 people in community in the form of questionnaires after getting informed consent. The role of pharmacy was not included due to possible non reliability. The results are expressed by analyzing the data using descriptive statistics.

Results: Experience and cost had been the main deciding factors for choosing the antibiotic for prescription. Third generation Cephalosporin was more prescribed and adults were exposed more to antibiotics with $81.56 \%$ and $75 \%$ from urban and rural respectively. Self medication was practiced by 14 out of 100 participants and more than $75 \%$ were not aware about proper use of antibiotics.

Conclusions: No significant difference was observed in prescribing pattern among doctors of various qualifications from both urban and rural setup and lack of knowledge about proper use of antibiotics was seen in community. Hence it is essential to create awareness by means of public education programmes, media and CME targeting both rural and urban areas.

Keywords: Antibiotic use, Self medication, Prescribing pattern, Antibiotic resistance

\section{INTRODUCTION}

Pharmacoepidemiology, a branch of pharmacology is a study of the use and effects of drugs in a large population. The beginning of the antibiotics era in 1940's was able to control infectious diseases which is still the leading cause for mortality especially in developing countries like India as per WHO health report 2007. ${ }^{1}$ This is said to be due to the emergence of new infectious diseases, re-emergence of old diseases and presence of intractable infectious diseases as per WHO report $2004 .^{2}$ On arrival to the market new antibiotics show good response which decline rapidly resulting in the development of resistance on long use. ${ }^{1}$ This may lead to the post-antibiotic era making treatment of infectious diseases more difficult. ${ }^{1}$ Many factors like inappropriate use of antibiotics, not following rational use of antibiotics by prescribing physician, lack of knowledge on appropriate use of antibiotics in the community, unregulated sale of Medicines and self medication by community have been attributed to the development of resistance to many antimicrobials resulting in Community and Hospital Acquired Resistant Infections by many studies. ${ }^{3-8}$ Other factors like lack of microbiology facilities, prescribing antibiotics for non bacterial infections like viral infection where it will not be effective and for patient's satisfaction have all led to overuse of antibiotics. ${ }^{9-12}$ Irrational use of antibiotics like Azithromycin etc. even for common cold in children which are usually due to virus was found on auditing the prescriptions collected from seven randomly selected pharmacies in a study. ${ }^{13}$

This has pushed back and reduced the use of cheap drugs with minimal side effects like co-trimoxazole, 
Quinolones, Penicillins and Macrolides etc. ${ }^{1}$ and increased the use of higher, costlier reserved antimicrobials like Vancomycin, Linezolid and Imipenem etc. The possibility of organisms developing resistant even to these can result in the necessity to discover newer ones. ${ }^{14}$ The increased prevalence of non-pathogenic E. coli resistant to Co-trimoxazole, ampicillin etc. especially in developing countries has been reported. ${ }^{15}$ All these factors can increase the financial burden which has already risen from 3763 crore rupees in 2005 to 6414 crore rupees in 2009 spent in purchasing antibiotics. ${ }^{10}$ There may be further increase if effective steps are not taken..$^{10,16}$

Increase in side effects due to over and inappropriate use of antibiotics will affect the quality of life and increase financial burden to the individual, to the society and to the Health care system. An alarming increase in antibiotic use and antimicrobial resistance especially in India is reported by a "Community based Surveillance of Anti microbial use and Resistance in the Resource constrained settings" by WHO based on the reports from 5 pilot projects three from India (Delhi, Mumbai, Vellore) and two from South Africa. ${ }^{17,18}$

As repeated co-ordinate surveillance studies have been recommended by WHO in this issue to curb the Antimicrobial resistance this study has been undertaken ${ }^{17}$ with the objectives of identifying the commonly used antimicrobials and the most exposed group of community in Pondicherry and the determining factors for inappropriate use of antimicrobials among professionals and community.

\section{METHODS}

After the approval of Institutional Research committee and Institutional Ethics Committee this cross sectional surveillance study was conducted for the period of 6 months in Pondicherry. With convenient sampling technique General Practitioners with M.B.B.S qualification, Post Graduates from various disciplines and super specialists of both genders from Urban and Rural areas were approached. They were requested to fill a questionnaire in English to analyze their prescribing pattern of antibiotics. ${ }^{19-22}$ To analyze the contributing factors by the community both males and females from urban and rural areas were explained and requested to answer a simply formulated questionnaire in vernacular language (Tamil) after getting their informed consent. The role of pharmacy was not included due to possible bias and possible unreliability in their responses as the laws against dispensing antibiotics without prescription are not generally strictly enforced. ${ }^{10}$ The results are expressed by using descriptive statistics for data analysis.

\section{RESULTS}

In Pondicherry, out of 50 physicians who participated in the study $76 \%$ were from urban and $24 \%$ from rural areas (Figure 1). In urban 14 (36.84\%) were with M.B.B.S qualification, $17(44.76 \%)$ with P.G qualification and 7 $(18.42 \%)$ with super-speciality qualification out of 38 participants. It was $7(58.33 \%), \quad 4(33.33 \%)$ and 1 $(8.33 \%)$ respectively out of 12 in rural (Figure 2). 22 physicians $(57.8 \%)$ from urban and $6(50 \%)$ from rural have said that most commonly encountered illness by them is Infectious diseases. 31 persons $(81.56 \%)$ in urban and $9(75 \%)$ in rural from the age group of 18-60 yrs have been treated by the physicians (Figure 3). It was third generation Cephalosporins which was highly prescribed in both urban and rural (55.28\% \& 25\%) areas. Penicillin group of antibiotics (Ampicillin \& Amoxicillin) were the second choice with $18.42 \%$ and $25 \%$ out of 38 among urban and 3 among 12 practitioners respectively (Figure 4).

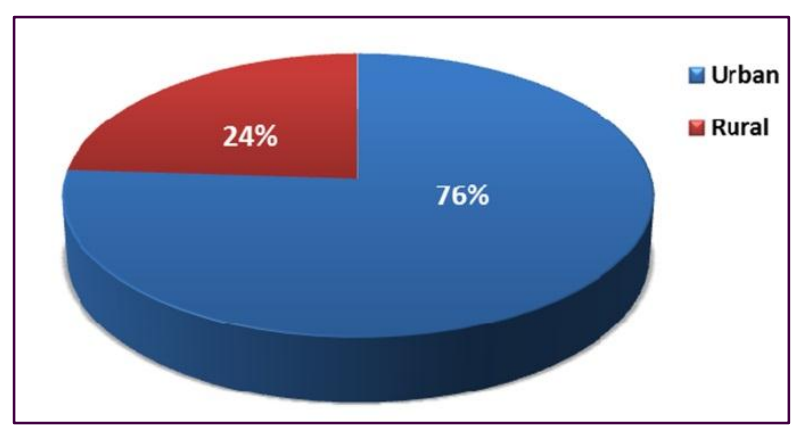

Figure 1: Distribution of study population.

Table 1: Distribution pattern of physicians and community in the study.

\begin{tabular}{|cccc|}
\hline & Urban & Rural & Total \\
\hline Physicians & $38(76 \%)$ & $12(24 \%)$ & 50 \\
\hline Community & $48(48 \%)$ & $52(52 \%)$ & 100 \\
\hline
\end{tabular}




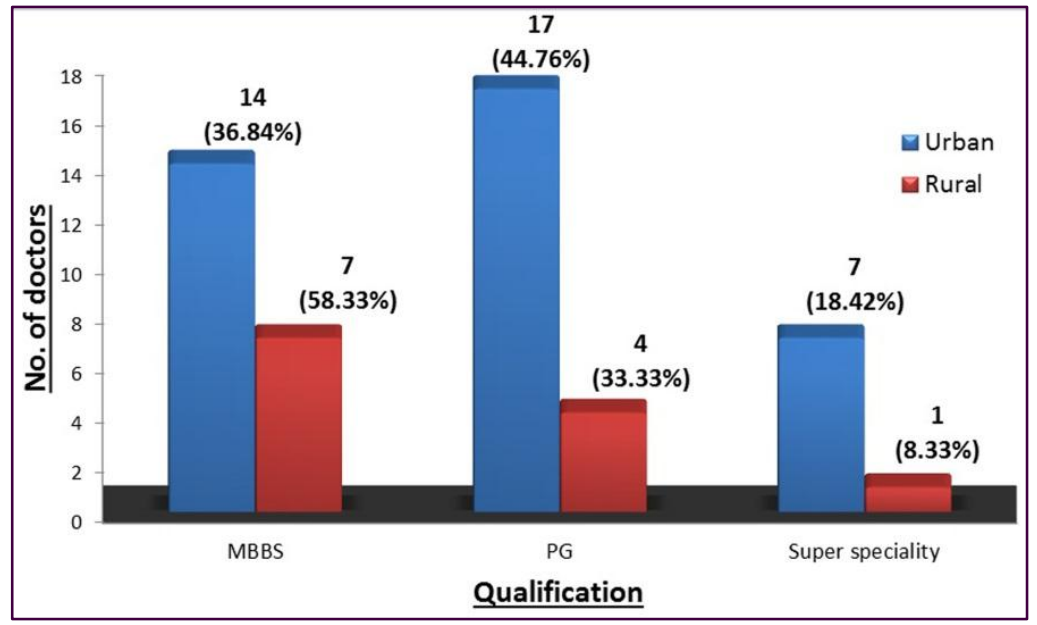

Figure 2: Doctors distribution qualificationwise.

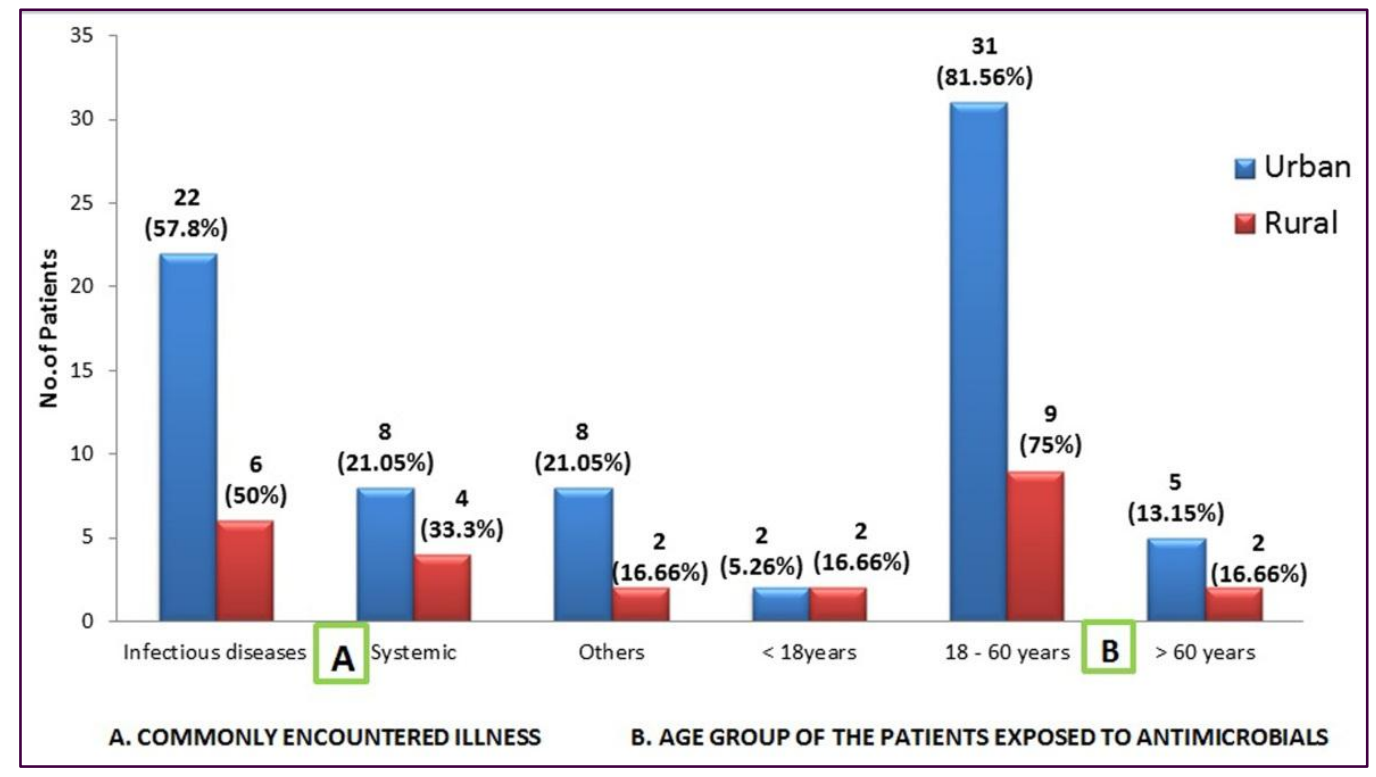

Figure 3: Commonly encountered illness and age group exposed to antimicrobial.

Experience and financial concern about patients were the main deciding factors for selecting antimicrobials by 16 and 15 physicians from urban and rural area respectively. Sensitivity test was preferred for choosing antibiotic only by about $6(15.7 \%)$ that too in urban alone. Prior antibiotic use and non reliability of microbial test have been stated to be the reasons for not opting sensitivity test (Figure 5). Evidence based selection was reported by 7 $(18.42 \%)$ from urban $1(8.33 \%)$ from rural. $5.26 \%$ out of 38 from urban and $25 \%$ out of 12 from rural have chosen antimicrobials empirically.

Single antibiotic was preferred by $78.78 \%$ physicians in urban and $70 \%$ in rural areas (Figure 6). $92 \%$ of physicians out of 50 have given their opinion that forming standard treatment guidelines and conducting periodic continuing medical education will increase rational use of antibiotics and can curb the danger of antimicrobial resistance (Figure 7). In the community out of 100 people $48 \%$ were from urban and $52 \%$ from rural. Among them 34 from urban $(70.83 \%)$ and 39 from rural (70\%) have been taking antimicrobials only on doctor's advice. But only $50 \%$ of them have taken complete course and $58.2 \%$ of urban and $64.10 \%$ of rural population have stopped antibiotics themselves on getting better without knowing the consequences (Figure 9). Only few have expressed cost being the cause (5 from urban \& 9 from rural) for their discontinuation. Pharmacist's suggestion and self medication by OTC purchase were seen in both the populations with $14.58 \%$ 


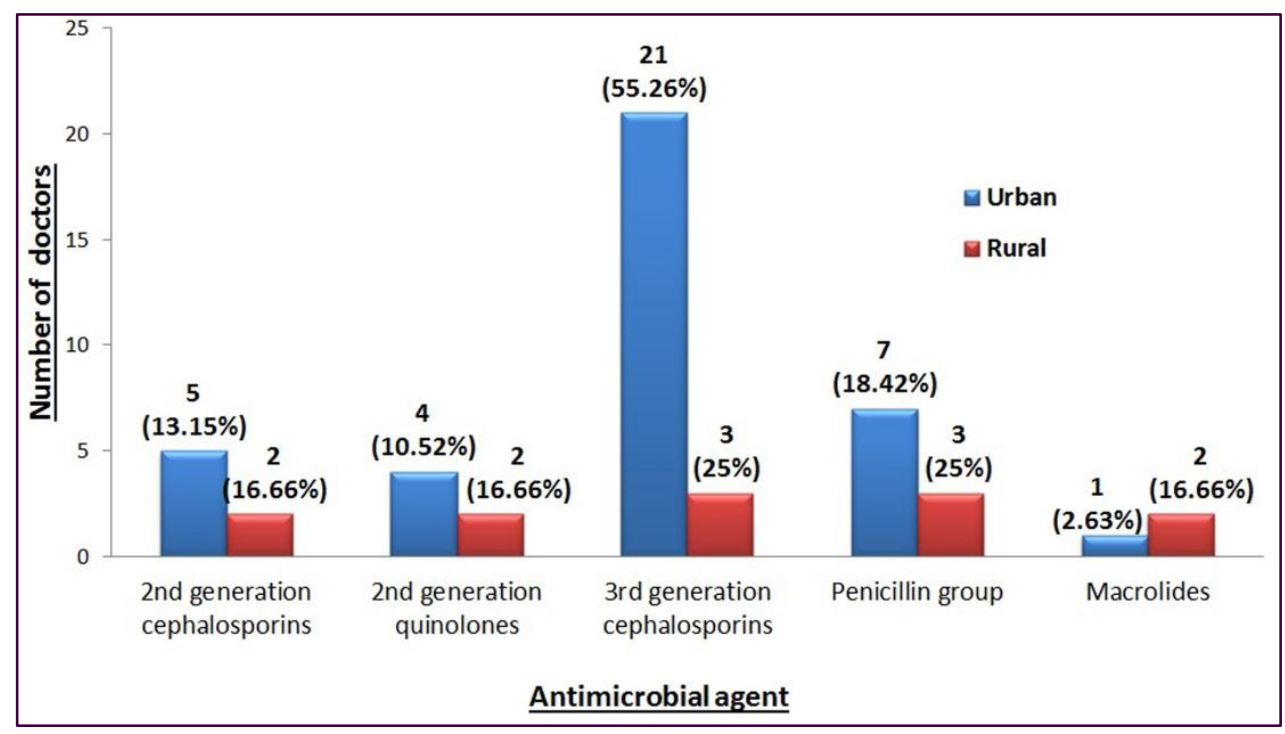

Figure 4: Highly used antimicrobial agent.

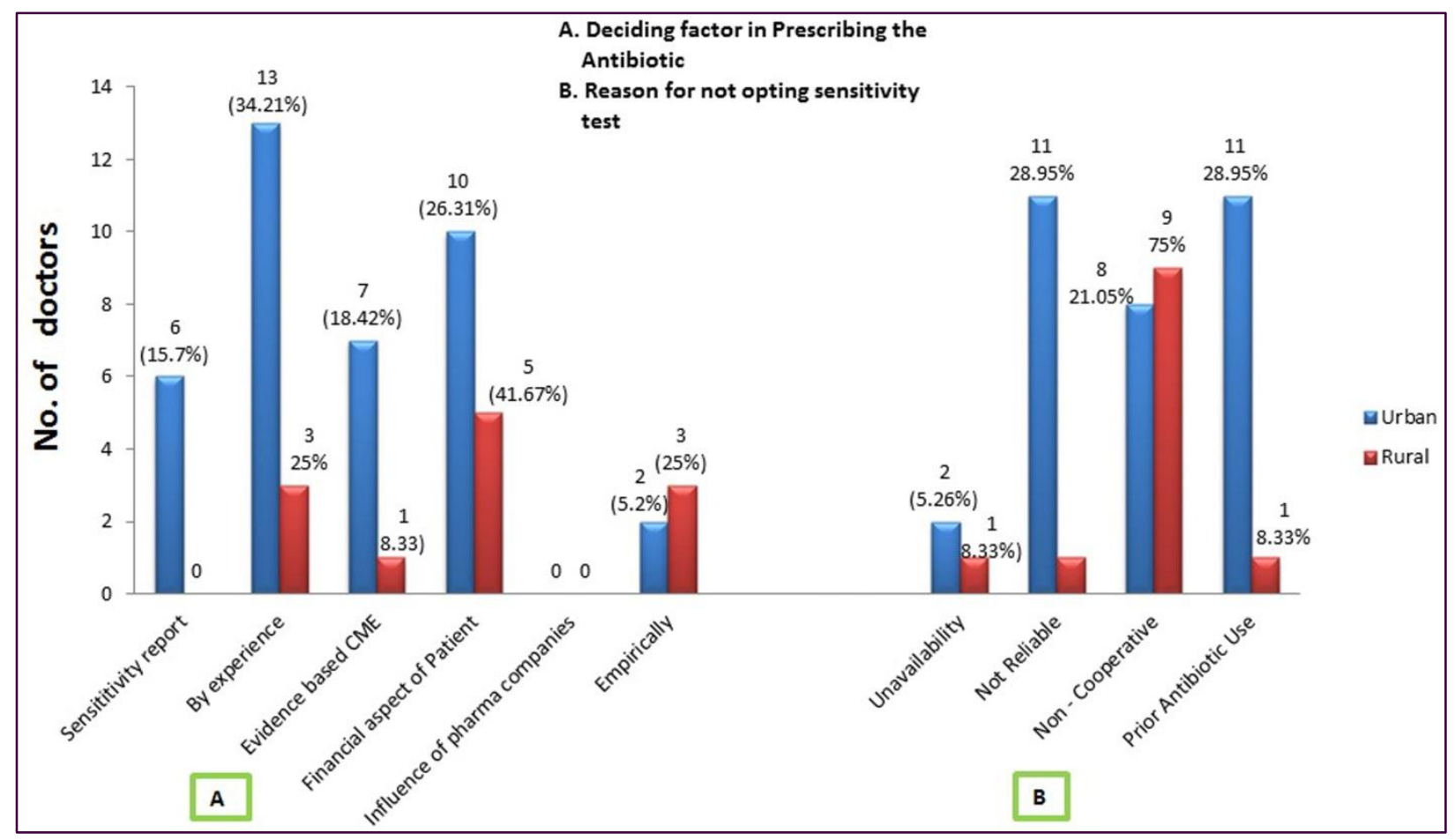

Figure 5: Deciding factors in antimicrobial prescription. 


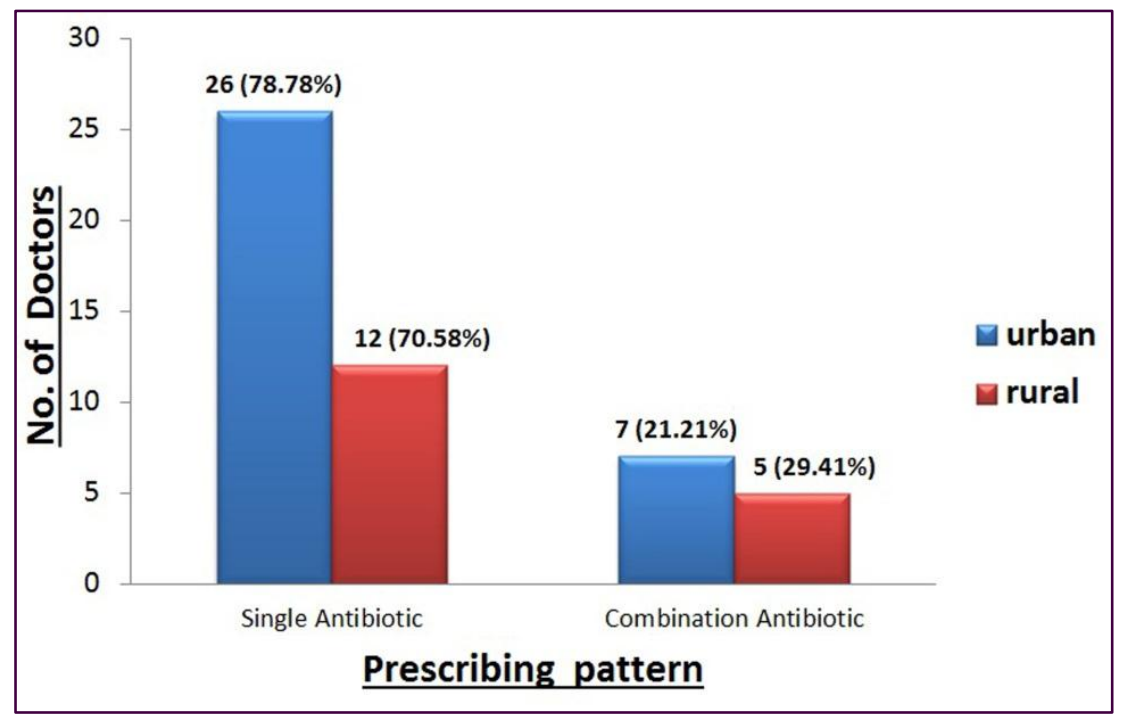

Figure 6: Prescribing pattern of doctors.

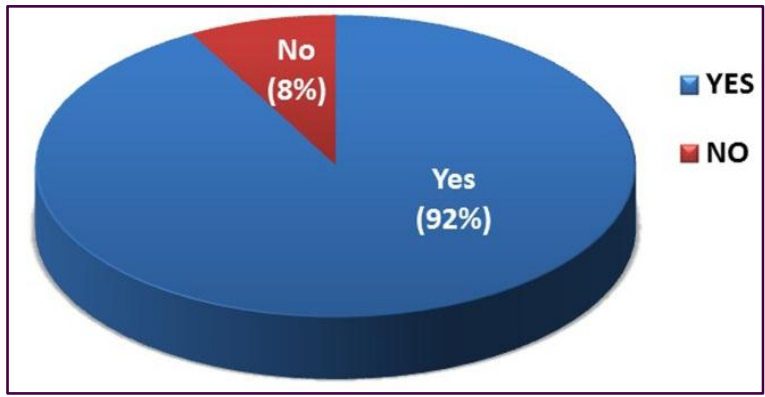

Figure 7: Effect of CME/ Standard guidelines on restricting antimicrobial resistance.

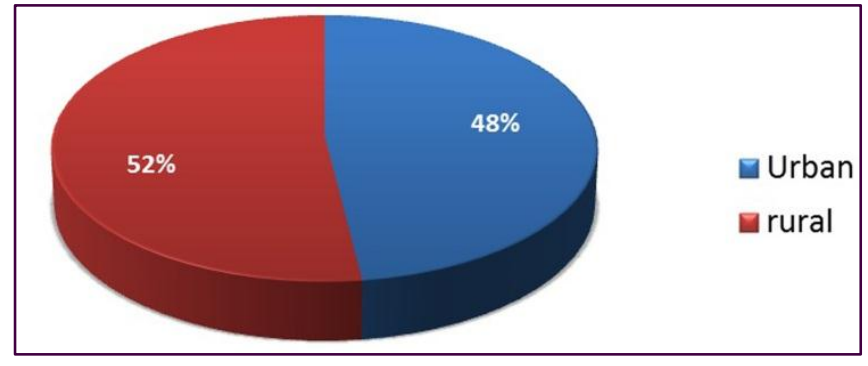

Figure 8: Distribution of study population (Community).

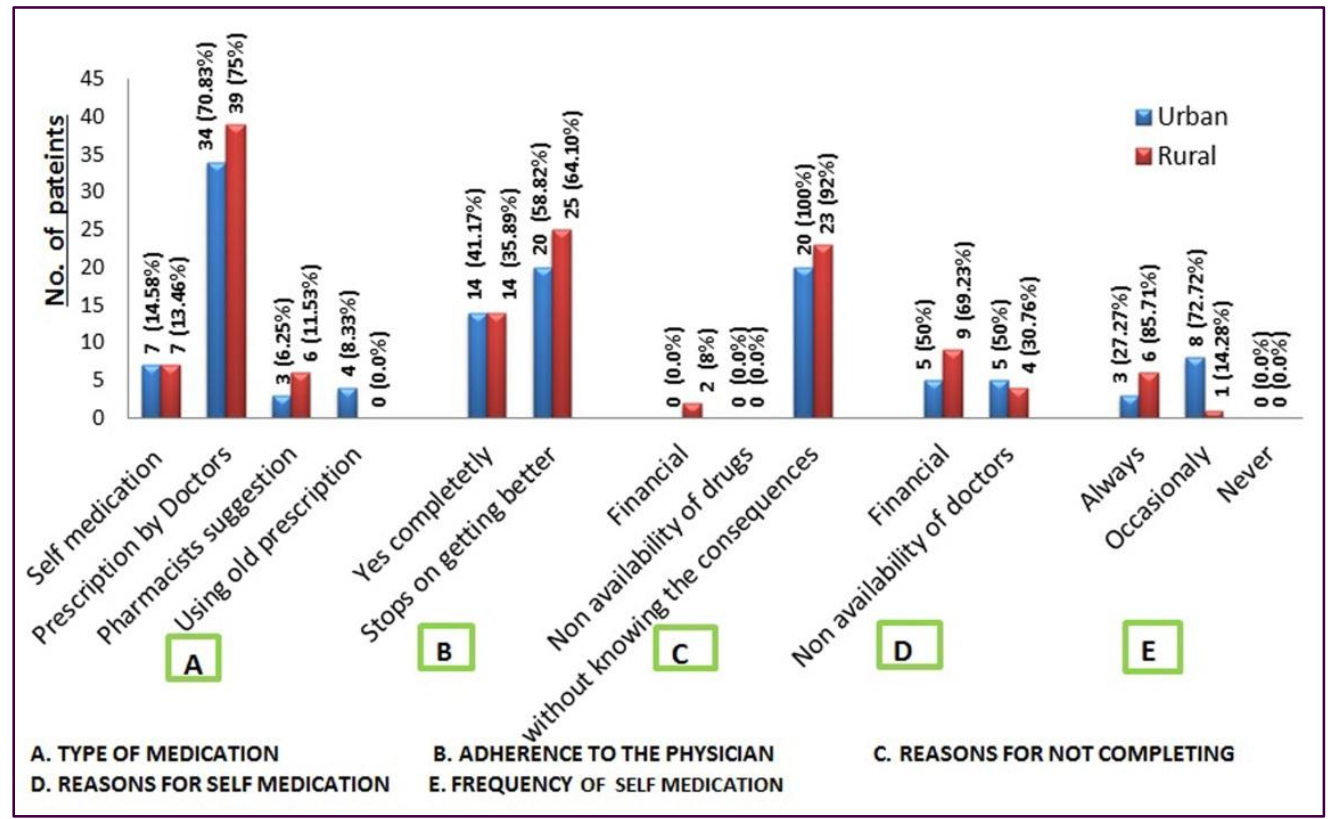

Figure 9: Medication practices in the study community. 


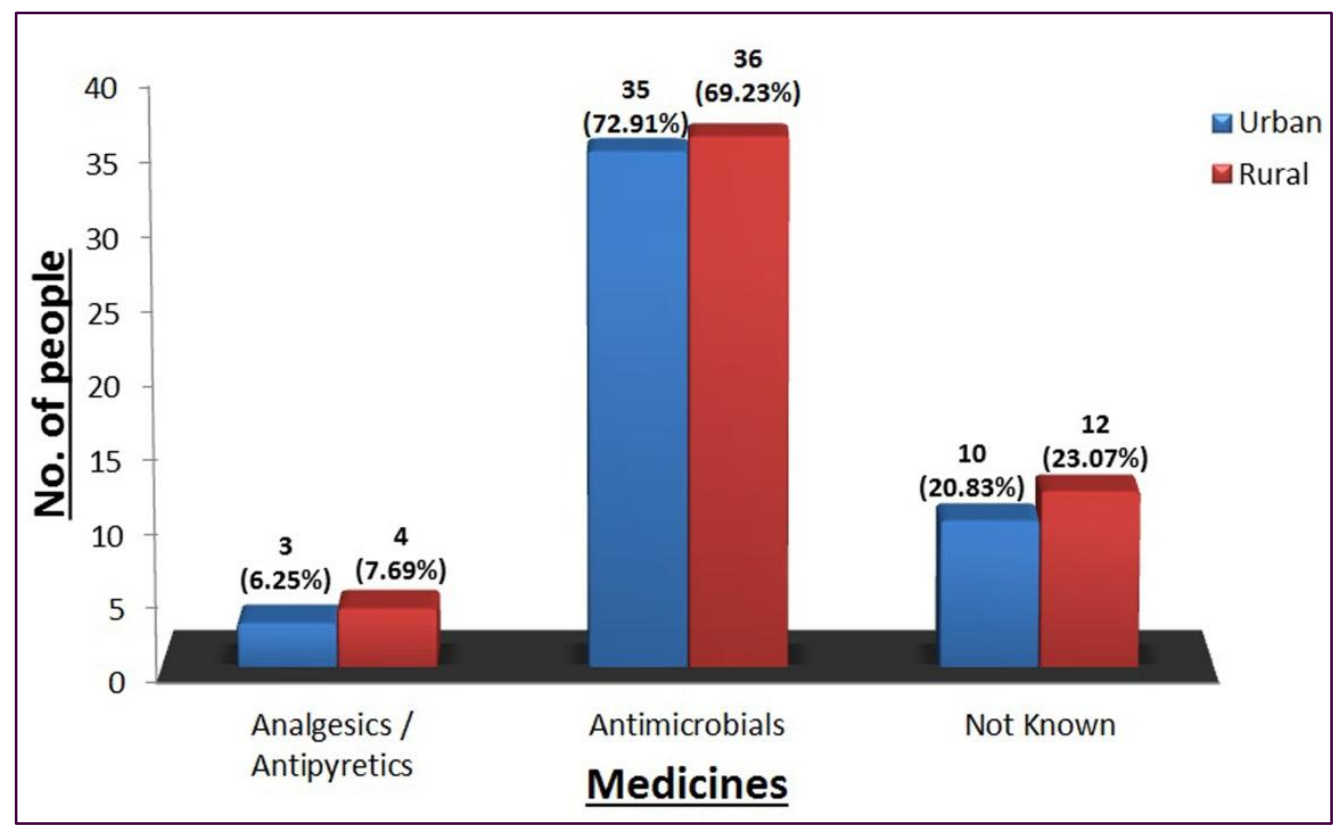

Figure 10: Medicines largely purchased over the counter (OTC).

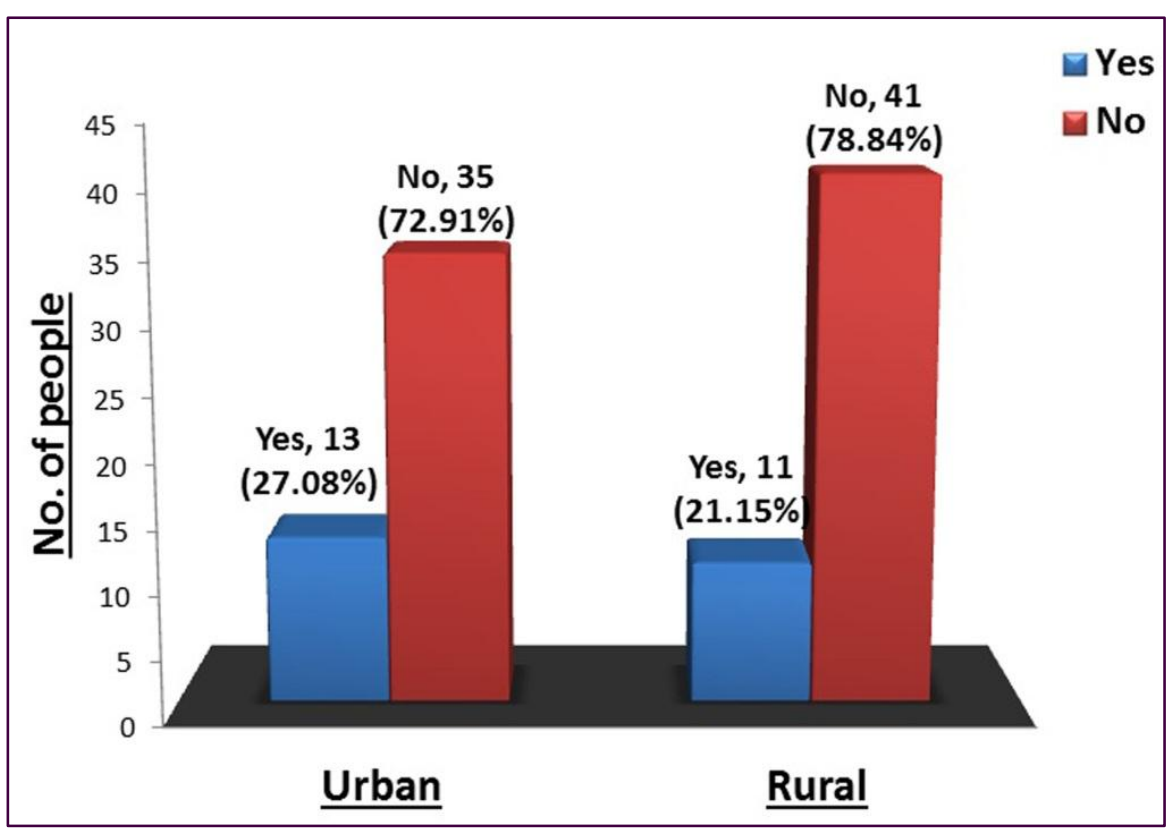

Figure 11: Awareness about antimicrobial use and antimicrobial resistance.

Our study shows that mostly antimicrobials are purchased Over the Counter (OTC) without prescription (urban $72.9 \%$ \& $69.23 \%$ rural). This is followed by analgesics forming $6.25 \%$ \& $7.69 \%$ in urban and rural respectively and about $20 \% \& 23 \%$ of both rural and urban people have been taking the drugs even without knowing what they are (Figure 10). Many in the study community (72.9\% urban \& $78.84 \%$ rural) have expressed their unawareness about the use of antibiotics and the consequences of their inappropriate use (Figure 11).

\section{DISCUSSION}

Out of 50 physicians participated in this study $76 \%$ were from urban and $24 \%$ from rural areas (Figure 1). Practising doctors with M.B.B.S / P.G / super-speciality qualification were more in urban compared to rural as 
quoted in many prior studies. It was noted that patients visited mostly for infectious diseases as per the statement given by the participated practitioners. Third generation cephalosporins were mostly prescribed with $55.2 \%$ in urban followed by penicillin group (amoxicillin \& ampicillin) and quinolones. In rural practice third generation cephalosporins and penicillin group were preferred equally followed by quinolones (Figure 4). A similar report of $95.85 \%$ of hospitalized patients receiving third generation cephalosporin has been shown in a prospective observational study done in a tertiary care level hospital in Erode, Tamilnadu. ${ }^{23}$ It is the antibiotic that is mostly purchased OTC in community pharmacies also. ${ }^{24}$ Whereas the community surveillance done in 2011 at Delhi has shown high consumption of quinolones. ${ }^{16}$ This change may probably be due to development of resistance to quinolones and the cause for over use of cephalosporin. This may put cephalosporin having wider action including against pseudomonas in to the danger of becoming ineffective. ${ }^{25}$ Experience [urban $(34.12 \%) \&$ rural $(25 \%)]$ and financial concern by the patients had been the main deciding factors for choosing antibiotic (Figure 5). Evidence based selection was seen more in urban practitioners than among rural (18.42\% urban, $1(8.33 \%)$ ] whereas 3 out of 12 practising in rural area have selected empirically compared to 2 out of 38 practitioners in urban. This may be due to less accessibility to CMEs and newer information which can be improved by extending such facilities to the rural areas also.

Surprisingly no one has said pharmaceutical company influence as one of the factor as reported in "Situation analysis of Antibiotic use and resistance in INDIA" by Global antibiotic resistance partnership - INDIA National working Group in March 2011. ${ }^{10}$ Only 6 persons $(15.7 \%$ ) has used sensitivity test that too only in urban in choosing the antibiotic. Non reliability of sensitivity report (27.27\%), prior antimicrobial use and unwillingness by patients due to cost and possible delay in initiating treatment have been stated as the reasons for not opting sensitivity test (Figure 5). This clearly substantiates the importance of making quick, less costly and reliable sensitivity tests easily available. $7 \%$ and $15 \%$ decrease in antibiotic use had been observed in Standard Treatment Guidelines (STG) Intervention Group and STG and Audit group respectively in a study conducted at Bangladesh. ${ }^{10}$ Reduction in inappropriate use of antibiotics and cost to the patients and hospital by formation and strict adherence of STG has been reported in a prospective study conducted in a tertiary care level hospital also. ${ }^{3}$

Similarly in our study $92 \%$ of physicians opined that strict adherence to STG and updating by means of structured public program will decrease over and inappropriate use of antibiotics and restrict emergence of antimicrobial resistance (Figure 7). Majority of physicians have prescribed single antibiotic. Even though it may be cost effective and might have been prescribed with the concern of financial strain for the patient in the mind, there can be a potential risk of resistance. Emergence of MRSA, MDR-TB, and quinolones resistant salmonella typhoid infection stand as good evidence and examples.

This study further confirms that infectious diseases are more prevalent in both urban and rural areas even with the discovery of many antibiotics and the most exposed age group is between 18- 60 yrs (Figure 3). As it is evident that the use of antibiotics is going to increase it is very much essential to control inappropriate use of antibiotics. Otherwise emergence of resistance can result in difficulty in controlling infection which will have a greater impact on the Health and Economy of developing Indian society. ${ }^{1,10}$

There was equal participation by urban and rural community people in our study (Figure 8). On analysis it was found that antibiotic was consumed on doctor's prescription by many in both urban and rural community (Figure 9). But many discontinued by themselves on getting better, without completing the entire prescribed course due to unawareness about its consequences. Only few have stated cost as a reason that too only in rural community (Figure 9). Out of 100 participants only 7 from urban and 7 from rural have accepted self medication with $14.56 \%$ and $13.46 \%$ respectively that too occasionally. Whereas out of 200 participants 142 persons $(71 \%)$ have been reported to take self medication in a randomised cross sectional survey conducted by Balamurugan E and Ganesh K at Pondicherry in 2011 . $^{25}$ This reduction in self medication in our study could not be clearly explained. It might be due to our's being a non randomized study with a small sample size. Pharmacist suggestion being the source for self medication was reported by 6 persons in rural participants than in urban with 3 persons. Old prescription was used by 4 persons from urban community only. These figures are significantly low in comparison to the results from a previous study. ${ }^{25}$ Non availability and cost have shown less influence in our study contrary to a review of prior studies. ${ }^{6}$ Antibiotics topped the OTC purchase in our study with $71 \%$ (Figure 10) which has also been reported in cross sectional study done in Uttar Pradesh with $54 \% .^{24}$

Lack of knowledge about the antibiotic use and their consequences was seen in our study also but it was slightly high in rural with $78.84 \%$ than in urban with $72.91 \%$ as has been reported as in some previous studies. $^{24,25}$

The study conducted by us being a non randomized one with small number of participants we had some restrictions. They were due to some practical difficulties met by us in collecting data from professionals and especially from community in explaining and making them understand. Even though convenient sampling having its own drawbacks was used for easy 
approachability we were able to identify significant results.

\section{CONCLUSION}

From our study the influencing factors for inappropriate and over use of antibiotics in professionals and community have been identified. Hence it is high time to take necessary steps to check them, so that development of antimicrobial resistance can be restricted which can affect the quality of life of people and economic status of the individual and the country. On the basis of our results it is crystal clear that creating awareness among community by public education as suggested in the "Report of the Intercountry Meeting, New Delhi, India, 13-15 July 2010" and by conducting CMEs regarding updated antimicrobial prescription pattern is very much needed. Other measures like framing of standard guidelines to physicians for rational use of antibiotic, making quick, reliable, less costly sensitivity tests easily available and restricting the OTC availability with strict law enforcement will definitely help to reduce inappropriate usage of antimicrobials and reduce or prevent the emergence of antimicrobial resistance. As no significant difference has been noted between urban and rural areas, both have to be targeted equally to achieve the goal.

\section{ACKNOWLEDGEMENT}

Authors wish to thank all the participants in this study especially the physicians who willingly shared their opinion. The help rendered by Mr. Sushiganeshkumar, Assistant Professor (statistics) from the Department of Community Medicine, Sri Venkateshwaraa Medical College Hospital \& Research Centre, Pondicherry in statistical analysis is thankfully acknowledged.

Funding: No funding sources

Competing interests: None declared

Ethical approval: The study was approved by the Institutional Ethics Committee

\section{REFERENCES}

1. Raghunath D. Emerging antibiotic resistance in bacteria with special reference to India. J Biosci 2008;33:593-603.

2. Gupta SK, Gupta P, Sharma P, Shrivastava AK, Soni SK. Emerging and re-emerging infectious diseases future challenges And Strategy. J Clin Diagn Res 2012;6:1095-100.

3. Aleykutty NA, Jayakar B, Suresh P, Leena PN, Mathews SM. Effect of regulations on the appropriate use of antibiotics. Int J Pharma Bio Sci 2011;2:32-5

4. Preeth M, Shobana J. Study of prescription pattern of antibiotics used in the management of various infectious diseases in Andhra Pradesh. Int Res J Pharm 2011;2:112-5.
5. Mathew BS, Fleming DH, Gupta M, Kumar R, Kumar D, Chandy SJ, Balraj V. An objective measure of antibiotic use for febrile illness in a rural pediatric population using high performance liquid chromatography. Indian J Med Res 2010;131:723-5.

6. Kumar AP, et al. Students knowledge of antibiotics a cross sectional study of students in Tamil Nadu. Int J Pharm Pharm Sci 2010;3:2323.

7. Varghese RT, Das R. Antimicrobial drug resistance in India, Possible causes. Asian Stud Med J 2010;1:151-4.

8. Shamshy K. Drug utilization of anti microbial drugs in pediatrics population in a tertiary care hospital in Erode, Tamil Nadu, India. Int J PharmTech Res 2011;3:1530-6.

9. Janaki R. Torvi, Dambal S. Drug prescription pattern in Pediatric outpatient clinic in a tertiary hospital. Curr Pediatr Res 2011;15:77-80.

10. Global Antibiotic Resistance Partnership-India (GARP-India). Situation analysis- Antibiotic Use and Resistance in India. Global Antibiotic Resistance Partnership-India National Working Group, March-2011. Available at http://www.cddep.org/sites/cddep.org/files/publi cation_files/India-report-web.pdf. Accessed 9 March 2012.

11. Peripi SB, Thadepalli VG, Khagga M, Tripuraribhatla PK, Bharadwaj DK. Profile of antibiotic consumption, sensitivity and resistance in an urban area of Andhra Pradesh, India. Singapore Med J 2012;53:268-72.

12. Khan NA, Abid M, Maheshwari KK, Kaviarasan PK, Mohanta GP. Antibiotic Prescribing Pattern in Department of Dermatology of a Teaching Hospital in Tamil Nadu. Indian J Pharm Pract 2010;3:18-21.

13. Moorthi1 C, Paul PR, Srinivasan A. Irrational use of antibiotics in paediatric prescriptions: A pilot study at community pharmacy in Erode City. Der Pharmacia Lettre 2011,3:171-7.

14. Shashikala, Kanungo R, Srinivasan S, Devi S. Emerging resistance to carbapenems in hospital acquired Pseudomonas infection: A cause for concern. Indian J Pharmacol 2006;38:287-8.

15. Bartoloni A, Cutts F, et al. Patterns of antimicrobial use and antimicrobial resistance among healthy children in Bolivia. Trop Med Int Health 1998;3:116-23.

16. World Health Organization. Promoting rational use medicines. Report of the Intercountry Meeting New Delhi, India, 13-15 July 2010. Available at http://www.searo.who.int/LinkFiles/Meetings_S EA-Drugs-161.pdf. Accessed 23 April 2012.

17. World Health Organization. Community-Based Surveillance of Antimicrobial Use and Resistance in Resource-Constrained Settings. Report on five pilot projects. 
WHO/EMP/MAR/2009.2. Available at http://www.who.int/medicines/publications/who _emp_2009.2/en/index.html. Accessed 18 January 2012.

18. Holloway K. Progress in the Rational Use of Medicines. Available at http://www.inrud.org/documents/upload/INRUD _News_Vol19_No1_Jul2009_Final.pdf. Accessed 18 January 2012.

19. Subbalaxmi MV, Lakshmi V, Lavanya V. Antibiotic Resistance - Experience in a Tertiary Care Hospital in South India. J Assoc Physicians India 2010;58 Suppl:18-22.

20. Bharathiraja R, Sridharan S, Chelliah LR, Suresh S, Senguttuvan M. Factors affecting antibiotic prescribing pattern in pediatric practice. Indian J Pediatr 2005;72:877-9.

21. Ganguly NK, Arora NK, Chandy SJ, Fairoze MN, Gill JP, Gupta U, et al. Rationalizing antibiotic use to limit antibiotic resistance in India. Indian J Med Res 2011;134:281-94.

22. Sivagnanam G, Thirumalaikolundusubramanian. P, Mohanasundaram.J. A survey on Current attitude of practicing physicians upon usage of antimicrobial agents in southern part of India. MedGenMed 2004;6:1.

23. Paul R, Sadiq S. A Prospective Study on Usage of Cephalosporins in Hospitalized Patients. IJPI's J Hosp Clin Pharm 2011;1:5.

24. Ahmad A, Parimalakrishnan S, Patel I, et al. Evaluation of Self-Medication Antibiotics Use Pattern among patients Attending Community Pharmacies in Rural India, Uttar Pradesh. J Pharm Res 2012;5:765-8.

25. Balamurugan E, Ganesh K. Prevalence and pattern of self medication use in coastal region of South India. BJMP 2011;4:a428.

doi: 10.5455/2319-2003.ijbcp003912

Cite this article as: Revathysaravanan, Muthukumar GLA. A surveillance study of antibiotic use in Pondicherry- 2012. Int J Basic Clin Pharmacol 2012;1:202-10. 